\title{
Citizens Take Charge: Concord, Massachusetts, Builds a Fiber Network
}

\section{Citation}

Talbot, David, Waide Warner, Susan Crawford, Jacob White. 2017. Citizens Take Charge: Concord, Massachusetts, Builds a Fiber Network. The Municipal Fiber Project, Berkman Klein Center for Internet \& Society Research Publication.

\section{Permanent link}

http://nrs.harvard.edu/urn-3:HUL.InstRepos:30201055

\section{Terms of Use}

This article was downloaded from Harvard University's DASH repository, and is made available under the terms and conditions applicable to Other Posted Material, as set forth at http:// nrs.harvard.edu/urn-3:HUL.InstRepos:dash.current.terms-of-use\#LAA

\section{Share Your Story}

The Harvard community has made this article openly available.

Please share how this access benefits you. Submit a story.

Accessibility 


\section{Case Study}

\section{Citizens Take Charge: Concord, Massachusetts, Builds a Fiber Network}
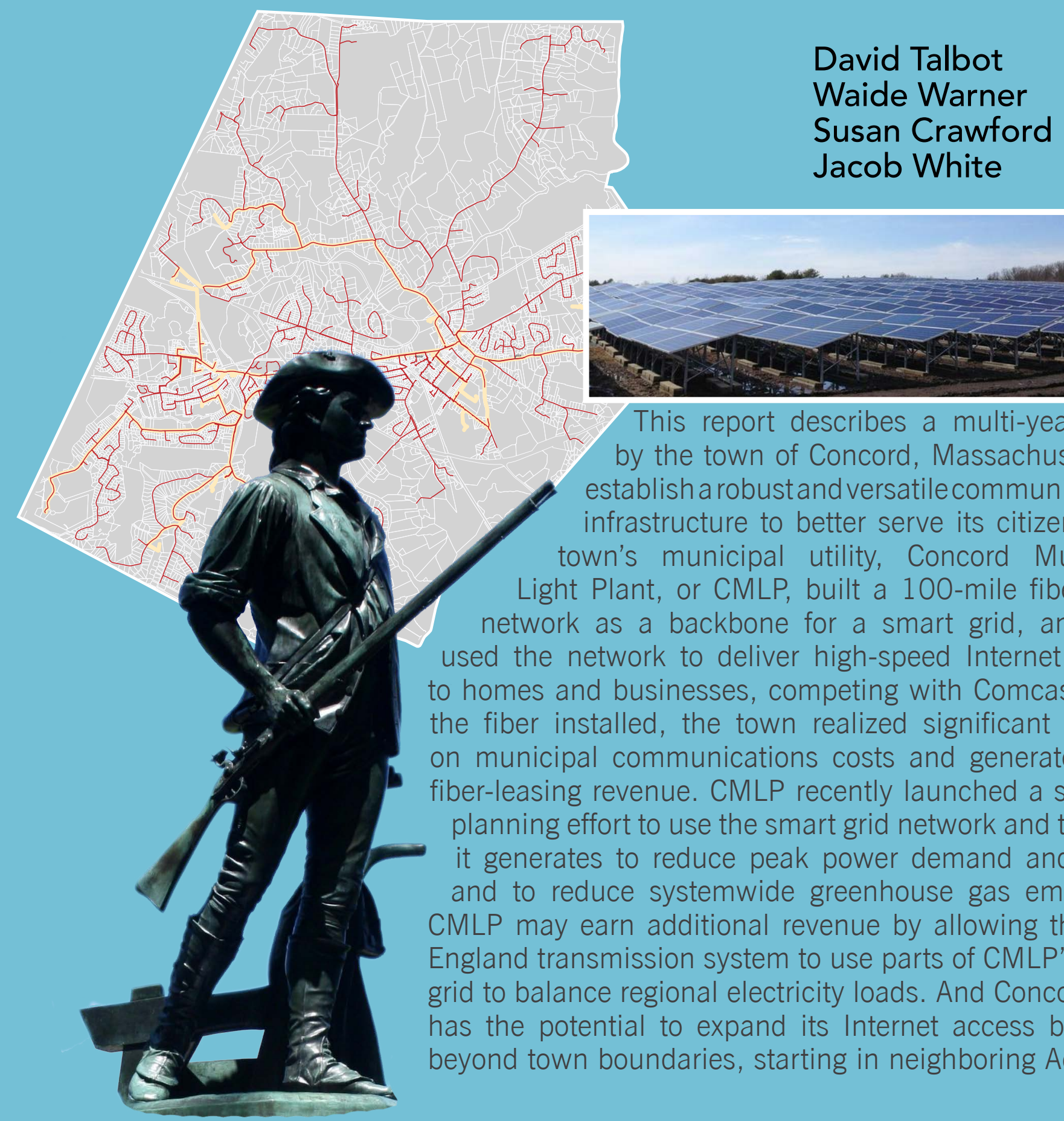

David Talbot Susan Crawford Jacob White

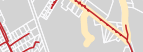

<

This report describes a multi-year effort by the town of Concord, Massachusetts, to establish a robustand versatile communications infrastructure to better serve its citizens. The town's municipal utility, Concord Municipal Light Plant, or CMLP, built a 100-mile fiber optic network as a backbone for a smart grid, and then used the network to deliver high-speed Internet access to homes and businesses, competing with Comcast. With the fiber installed, the town realized significant savings on municipal communications costs and generated new fiber-leasing revenue. CMLP recently launched a strategic planning effort to use the smart grid network and the data it generates to reduce peak power demand and costs, and to reduce systemwide greenhouse gas emissions. CMLP may earn additional revenue by allowing the New England transmission system to use parts of CMLP's smart grid to balance regional electricity loads. And Concord now has the potential to expand its Internet access business beyond town boundaries, starting in neighboring Acton. 


\section{Executive Summary}

Residents of Concord, Massachusetts, have a history of triggering important initiatives in geopolitics, American literature, and now municipal fiber optic infrastructure. After a decade of studying how to improve the town's Internet access-and encountering significant opposition from the telecommunications industry-the town ultimately decided to take control of its communications future by constructing its own 100-mile fiber optic network. The project started in 2009 when voters authorized the town's municipally owned electric utility (Concord Municipal Light Plant, or CMLP) to build the network as part of a $\$ 3.9$ million smart grid able to support control and sensor systems that can improve reliability, reduce costs, and control peak-hour energy consumption. Next, in 2013, the town borrowed $\$ 600,000$ to fund the startup of an Internet access business, called Concord Light Broadband. The town began making fiber connections to subscribers' premises in early 2015.

By the end of 2016 CMLP was serving about 750 customers with service of up to $200 \mathrm{Mbps}$ upload and download. Today the town's network is also helping the town avoid $\$ 108,000$ in annual communications costs and generate $\$ 88,000$ in leasing revenue. On the smart grid side, the fiber has allowed CMLP to more reliably control electric heat-storage systems in customers' homes. A contractor serving the town believes CMLP could generate $\$ 125,000$ in annual revenue by allowing New England's transmission system to time when these heaters, plus electric hot-water heaters, are switched on and off-an effort that would help balance electricity supply and demand in the region.

Paybacks on the town's project are not yet fully covering debt service and operating costs, but it is still early days for Concord's network. Fiber-based smart grids have realized significant paybacks elsewhere, notably in Chattanooga, Tennessee. (See companion report: "Smart Grid Paybacks: The Chattanooga Example.") Fiber lasts 30 years, and Concord's smart grid debts will be paid off after 15 years. The town has recently launched a strategic plan in part to guide use of the smart grid to reduce peak demand, reduce operating costs, enhance revenue, and cut greenhouse gas emissions. 


\section{Key Findings}

- In 2009 Concord Municipal Light Plant (CMLP) started work on a 100-mile fiber optic and wireless network to provide backhaul for a smart grid. The fiber passes 95 percent of homes and businesses in town.

- The $\$ 3.9$ million project was paid for by electric ratepayers through annual payments that started at $\$ 418,000$ per year and will decline to $\$ 207,000$ in the 15 th and final year of payments. The fiber will last for at least 30 years.

- In a second step, CMLP established a telecommunications division, called Concord Light Broadband, and borrowed $\$ 600,000$ to fund startup costs of an Internet access business and fiber connections to customers.

- CMLP offers residential data plans of up to $200 \mathrm{Mbps}$, upload and download, for $\$ 89$ monthly with a two-year agreement. CMLP competes with Comcast. CMLP doesn't offer phone or video, but does provide much faster data upload speeds than does Comcast.

- The project is still being built: at the end of 2016, Concord Light Broadband served about 750 customers (a "take rate" of about 12 percent of the 6,000 customers CMLP estimates could take service) and earned 2016 revenue of $\$ 560,000$, slightly less than operating costs of $\$ 583,000$. (In 2016 the division also paid debt service of $\$ 60,000$, including a $\$ 50,000$ payment on principal.)

- CMLP's fiber helped the town save $\$ 108,000$ in annual police and school communications costs and generated $\$ 88,000$ in leasing revenue from a private school and two telecom companies.

- CMLP is only in the early stages of realizing the benefits of its fiber. The utility is now engaged in studies on how to use the infrastructure to realize more cost savings, increase revenue, provide new services, and reduce emissions in the coming decades. 


\section{I: Concord's Internet Access Problems}

By the rude bridge that arched the flood,

Their flag to April's breeze unfurled,

Here once the embattled farmers stood,

And fired the shot heard round the world.

Engraved on a granite obelisk, Ralph Waldo Emerson's 1837 "Concord Hymn" memorializes the famous battle at the North Bridge over the Concord River on April 19, 1775, a flash point of the Revolutionary War. The bones of British Redcoats remain interred near where they were felled by bullets fired from muskets of the Minutemen-citizen-soldiers of the region. Concord's place in American history was burnished when it became the seat of the transcendental literary movement, home to Emerson, Louisa May Alcott, and Henry David Thoreau.

National parks and land trusts still impart a rural feel to Concord. The downtown is a mix of historic buildings and low-slung retail establishments. Today, the town has about 16,500 residents spread over 26 square miles. It is generally affluent, with a median household income of $\$ 132,700$, compared with the national average of $\$ 53,600$. Despite its affluence, Concord had a big problem: inadequate Internet access. At the turn of the millennium, most of Concord had only dial-up service providing $56 \mathrm{Kbps}$ connection speeds, DSL service near the town center providing about $1 \mathrm{Mbps}$, and cable TV service from a Comcast predecessor, Cablevision, that didn't offer any Internet access plan.

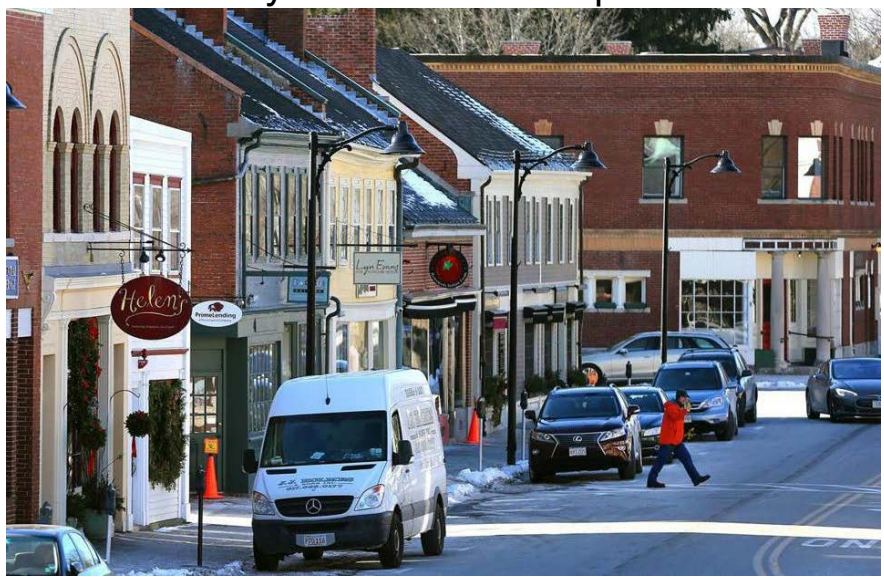

Downtown Concord
The town's dispersed development patterns made Concord a relatively expensive place for telecommunications providers to do business. Making matters worse, in 1986 the town adopted an ordinance requiring utility lines to be buried underground in many areas. Approximately half of the structures in Concord were required to receive utility service via underground conduit, typically two-inch PVC pipe. ${ }^{2}$ The cost of burying wires is significantly higher than aerial installation on poles, the most common method. Private property owners were responsible for paying for installation of conduit traversing their property, a job that can cost several hundred dollars or more, depending on the site.

As late as 2001, only one DSL provider, HarvardNet, used technology that could provide speeds faster than $56 \mathrm{Kbps}$ to premises beyond 18,000 feet from the telephone office in downtown Concord. ${ }^{3}$ When HarvardNet ran into financial trouble in 2001, Concord residents David Clark (an MIT research scientist who was the Internet's chief architect in the mid-1980s) and David Allen bought the business for $\$ 1$. For a time, this volunteer "OurConcordNet" offered peak speeds of $784 \mathrm{Kbps}$ "and was the only broadband game in town" for subscribers at the town's edges. ${ }^{4}$ Verizon bypassed Concord when it installed its FiOS-branded fiber optic network in the region, including in the bordering municipalities of Maynard, Billerica, Lincoln, and Lexington.

There were some bright spots: some public buildings in town had good connectivity. By the late 1990s, the town had built a fiber loop serving municipal buildings, avoiding annual private circuit leasing costs of about $\$ 600,000$. $^{6}$ Town leaders began considering whether to build a wider fiber network to provide Internet access. To do so, they turned to Concord's locally owned electric utility. 


\section{CONCORD MUNICIPAL LIGHT PLANT}

The Concord Municipal Light Plant is one of 41 municipal light plants (MLPs) providing electricity to towns and cities in Massachusetts. MLPs were typically established in the 1890s and early 1900 s, because private electricity companies refused to provide service to small or thinly developed towns like Concord. MLPs have a variety of governance models. Concord's is a department of the town but has a rate-setting board appointed by the town manager.

Few of these MLPs still generate power locally, but all operate power distribution grids. Like other MLPs, the one in Concord owns poles and conduit, through which it runs power lines and can also run fiber. In 1996, the Massachusetts Legislature amended state law to allow MLPs to operate telecommunications services. ${ }^{7} \mathrm{Al}-$ though MLPs are well positioned to provide affordable high-speed Internet service, few have done so. ${ }^{8}$

Dan Sack, general manager of CMLP from 1988 until his retirement in 2010, made it his mission to solve Concord's Internet access problems. When Concord's Cable Television Committee was renegotiating its contract with the local cable

Benefits From an Earlier Fiber Loop

In the 1990s Concord installed a "municipal fiber loop" connecting the library, police department, two community centers, and two fire stations. The fiber was later connected to CMLP's substations and Concord's schools. Concord also used the fiber to upgrade the local community access TV studio and transition the municipality's phone system to a Voice over Internet Protocol (VolP) system.

Town officials estimate that the municipal loop saves the town $\$ 600,000$ in annual leasing charges that it would otherwise pay private telecommunications companies. (The smart grid and Internet access project later enabled additional savings and revenue, as noted elsewhere.) franchise holder, Cablevision, Sack made sure the new contract would not contain language precluding CMLP from entering the telecommunications business.' To study next steps, the town formed first one committee, then another, called a Telecommunications Study Committee, which in early 2003 found strong local interest in better Internet access. $^{10}$
In opposing the plan, Comcast worked with a Boston think tank called the Beacon Hill Institute $(\mathrm{BHI})$-named for high ground in Boston that had been the redoubt of the British before their rout by colonists in March of 1776 . In March of $2004 \mathrm{BHI}$ issued a 43-page report opposing the town's efforts. ${ }^{13} \mathrm{BHI}$ launched in 1991 as the research arm of Suffolk University's Department of Economics and describes itself as a think tank "grounded in the principles 
of limited government, fiscal responsibility and free markets." ${ }^{\prime 4} \mathrm{BHI}$ is historically funded by conservative organizations. *

BHI's report predicted Concord's project would lose money and be rendered obsolete by emerging technologies. In some ways, the report was misleading. First, while a full fiber-to-the-home (FTTH) and video service would indeed be expensive, this was neither Concord's only option nor the approach the town ultimately pursued. Second, the upcoming Concord vote was only about authorizing CMLP to enter the business, not any particular plan or expenditure. Third, while the report pointed to what it said were failed municipal Internet access projects across the country, most such projects are providing substantial community benefits. ${ }^{17}$ Finally, BHI's report incorrectly claimed that an alternative communications technology called broadband over power lines might render Concord's FTTH project useless. While it is possible to send radio frequencies along power lines, the approach is subject to interference. ${ }^{18}$ Fiber has always been a superior communications medium.

In March and April of 2004, NECTA used the BHI report as part of a campaign opposing CMLP's entry into the telecom business, sending mailings to residents and publishing advertisements in the local paper, the Concord Journal. ${ }^{19}$ Leaders of the two organizations also made a joint appearance at a Concord public hearing. And many residents reported receiving phone calls asking questions designed to elicit opposition, with statements such as: ${ }^{20}$

- "Your Light Plant has not released figures, but estimates are that it will cost $\$ 12$ million to \$18 million."

- "Beacon Hill Institute has done a study and concluded that it is highly, highly risky. They estimate there is a $60 \%$ probability it will fail."

Concord brushed the campaign aside. A group of citizens, led by Allen, established a website backing CMLP. ${ }^{21}$ In April of 2004, Town Meeting voted overwhelmingly to approve CMLP's entry into the business. But as CMLP studied its options, it became clear that $\mathrm{BHI}$ had been right about one thing: launching a townwide Internet access, video, and phone service (so-called "triple play") would be expensive. The town issued an RFP to examine its options and hired Uptown Services of Boulder, Colorado. The consultant predicted such a project would cost $\$ 19.6$ million and not turn a profit. ${ }^{22}$

Concord's leaders also confronted a Catch-22. They'd apparently provoked Comcast into providing better service in town, which was a good thing. But the existence of this improved service hurt the argument for investing in a competing one. So town leaders started thinking more broadly about fiber's potential. CMLP turned to the possibility of building a fiber loop as the backbone of a smart grid, thus improving reliability and laying the foundation for more efficient and less wasteful electricity service while also allowing the town to provide Internet access service and other benefits.

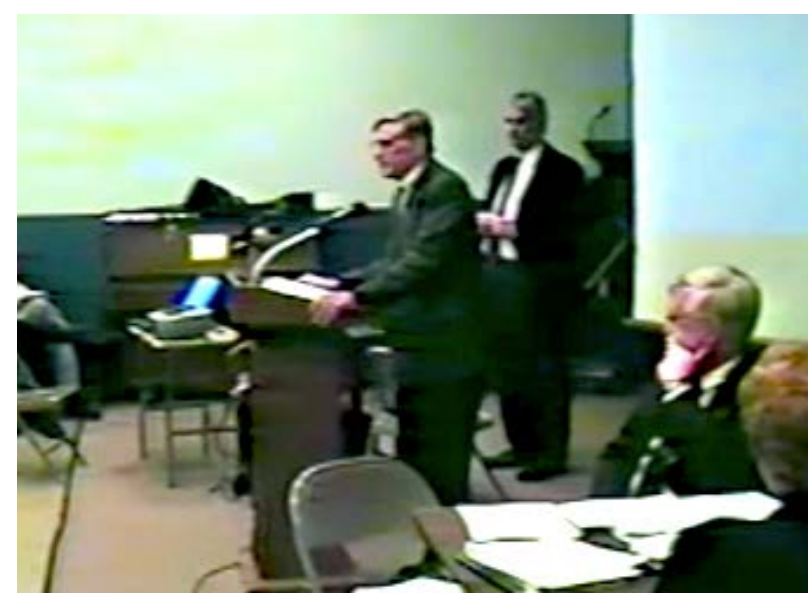

David G. Tuerck (left), BHI's executive director, and Paul Cianelli, president of the New England Cable \& Telecommunications Association, speak at a 2004 public hearing in Concord.

\footnotetext{
* Through 2003, BHI's only publicly listed donor was the Roe Foundation, founded by Thomas Roe, who also was a founder of the conservative State Policy Network and early funder of the Heritage Foundation. In 2004, BHI also received money from the Lynde and Harry Bradley Foundation, a conservative organization. ${ }^{15}$ In later years, $\mathrm{BHI}$ received funding from the Koch Foundation, which funds conservative political candidates and fossil-fuel lobbying efforts. In December of 2015, Suffolk University severed ties with $\mathrm{BHI}$ in part because of its funding sources. ${ }^{16}$
} 


\section{II: Concord Builds a Smart Grid}

A smart grid uses two-way communications networks and digital controls to allow optimal management and control of electricity distribution. Applications include sensing outages, tightly regulating electricity flows for efficiency, managing the addition of wind and solar power and storage systems, and shutting off loads (with consent of customers) during peak times. ${ }^{23}$ units, CMLP saw another use for a smart grid. CMLP believed it could cut peak demand using new customer thermostats that CMLP could control, via a smart grid, to reduce air-conditioning demand in summer. CMLP estimated that each megawatt of reduced demand at the annual peak would save CMLP $\$ 120,000 .^{26}$

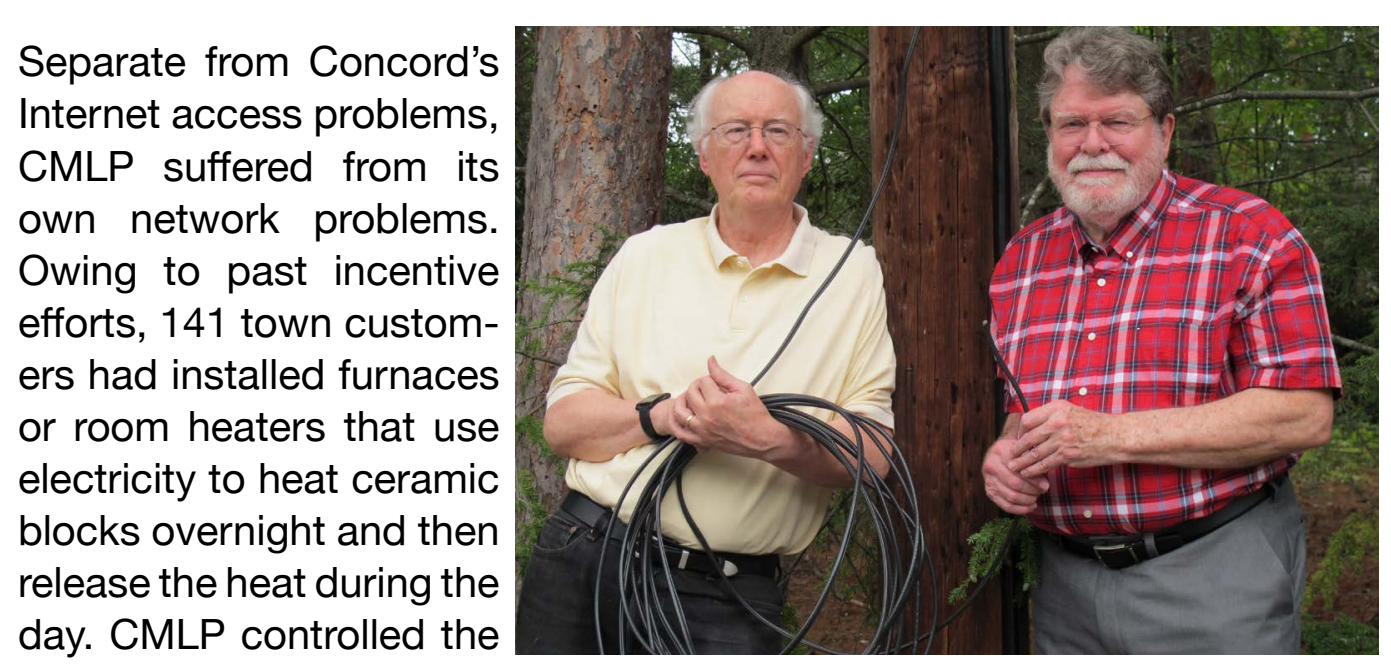
timing of these "charging" periods; charging all of them simultaneously requires 3 megawatts of electricity, about 10 percent of Concord's average daily peak demand. ${ }^{24}$

But CMLP was using the copper telephone network to control these systems. This approach was becoming unreliable. Worse, the company that made the control systems on the heaters went out of business. ${ }^{25}$ (CMLP has similar controls on 360 electric hot water heaters to prevent them from reheating during peak periods.) In addition to upgrading how it controlled these

\section{CONCORD'S SMART GRID BUDGET}

- Labor for construction and technical services - \$2.0M

- Fiber and other materials and systems - \$1.4M

- Smart grid wireless nodes - $\$ 250,000$

- Equipment and programmable thermostats - $\$ 180,000$

- Engineering services - $\$ 125,000$

- Substation renovation for equipment rooms - $\$ 100,000$

- Technician's vehicle and test equipment - \$100,000

Total estimate with $10 \%$ contingency: $\$ 4.5 \mathrm{M}$

Actual installed cost: $\$ 3.9 \mathrm{M}^{28}$
Before choosing fiber, CMLP ran a $\$ 48,000$ pilot project to test broadband over power lines but concluded that this was both unreliable and unable to support real-time smart grid applications. ${ }^{27}$ While all-wireless technologies are capable of providing smart grid backhaul, CMLP concluded a fiber-based network could best serve long-term utility needs and also provide world-class Internet access in the future. In April of 2009, Town Meeting approved, by a vote of 200 to 55 , a $\$ 4.5$ million bond authorization to design, purchase, and install a smart grid. The vote came weeks after the U.S. Congress passed the American Recovery and Reinvestment Act, creating a $\$ 787$ billion stimulus program. Concord applied for a smart grid grant, but the application was denied. The system ultimately cost $\$ 3.9$ million and was financed with a general obligation bond.

\section{FINANCING}

In 2011 Concord financed the project with a \$3.9M, 15 -year general obligation bond. Payments in the first year totaled $\$ 418,567$; the final payments, in 2026, will total $\$ 207,000 .^{29}$ Not counting paybacks and savings experienced by CMLP and the town at large, the cost translates into an average of about $\$ 4$ on each customer's monthly electric bill in the first year, declining to $\$ 2$ in the 15th year. 


\section{CONCORD'S SMART GRID FIBER NETWORK}

Concord's $\$ 3.9$ million smart grid network consists of approximately 100 miles of fiber and 80 fiber-connected wireless "gateways" mounted on utility poles. These gateways, in turn, communicate with 600 wireless repeaters integrated into streetlights. The repeaters communicate with special customer meters called smart meters, which can in turn control devices in the home or business and send data back to CMLP. The system already allows CMLP to precisely control the dispatch of 3 megawatts of electricity to 141 electric heating units and 360 electric hot water heaters. In the future, the smart grid will allow Concord to issue instructions to thermostats or other devices if the customer permits such control to reduce townwide demand during peak times.

The Concord system includes a customer interface permitting real-time views of electricity usage. Concord's fiber network is technically called a gigabit passive optical network, or GPON, and uses hardware from Calix. A consultant, Uptown Services, designed the network. Nexgrid provided technology and Nextgen constructed the network. ${ }^{30}$ So far the utility has installed 878 smart meters that collect data every 15 minutes. In 2016 CMLP launched a study of these data to inform changes to its rates and incentives to meet goals of reducing emissions, cutting peak loads, and maintaining adequate revenue.

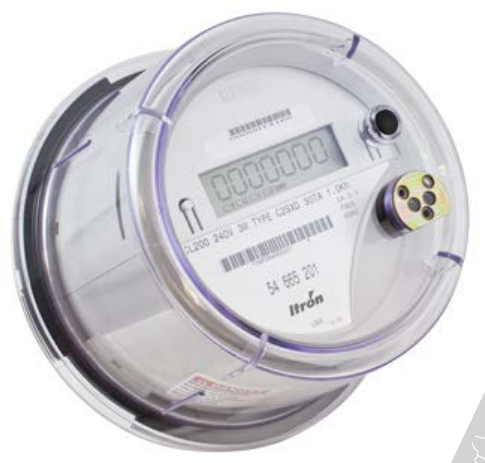

Smart meters allow twoway communication.

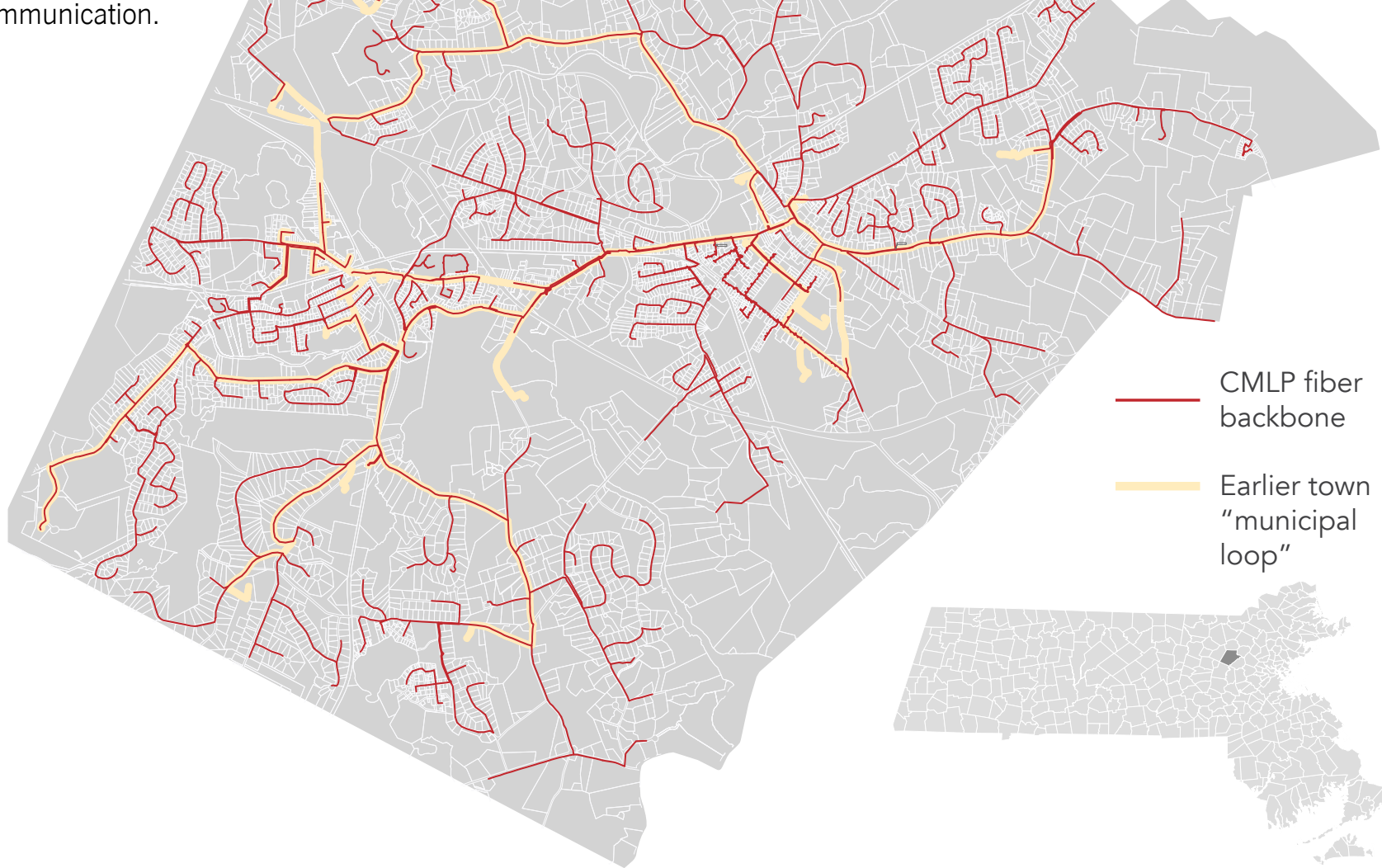




\section{III: Providing Internet Access}

While the smart grid fiber loop was being installed, CMLP began considering how to provide townwide fiber-based Internet access service. CMLP's board asked the town's CIO, Mark Howell, to prepare a feasibility study.

With the smart grid complete, the fiber passed 95 percent of Concord's residences. Howell predicted that making fiber connections to customers would cost CMLP between $\$ 600$ and $\$ 1,400$ per household (plus the cost of any needed conduit, for which the property owner would be responsible).

His study concluded that the costs of offering pay television or phone service were too high for a moderately sized town to contemplate offering. He suggested CMLP provide Internet access only, and predicted that up to approximately 2,000 customers would take such service. The study emphasized CMLP's com- petitive advantage, including its existing relationships within Concord and reputation for providing high quality customer service. Howell devised a plan for a gradual buildout. The town would make installations and pay for operations with the incrementally increasing revenue. The study concluded that if CMLP added 15 customers a month, the project would start turning a profit in 30 months. ${ }^{31}$

CMLP asked Town Meeting to approve a $\$ 1$ million bond to connect individual customers and launch the Internet access business. On March 13, 2013, Town Meeting unanimously approved the debt authorization. CMLP has drawn $\$ 600,000$ of the authorized $\$ 1$ million in debt, and started making connections in 2014. By the end of November, 2016, Concord Light Broadband had 750 customers and a staff of five. In 2016 CMLP earned $\$ 560,000$ in revenue from those customers and spent $\$ 583,000$ on

\section{CMLP's Internet Access Offerings}

CMLP offers residential and business data plans, charges a $\$ 150$ installation fee, and requires a two-year commitment. Customers subject to the town's "undergrounding" ordinance must pay to install conduit. ${ }^{32}$ Unlike Comcast, CMLP doesn't offer phone or video plans. CMLP has 8,320 electric customers, of which about 6,000 could be served by CMLP's Internet service (others are municipal offices, customers in multi-unit dwellings that have signed exclusive agreements with Comcast, or in developments where fiber is not yet installed). So far 750 customers have subscribed.

CMLP RESIDENTIAL PLANS

\begin{tabular}{|l|l|}
\hline Download/Upload Speeds & Prices \\
\hline $25 / 25 \mathrm{Mbps}$ & $\$ 49.95$ \\
\hline $50 / 50$ & $\$ 64.95$ \\
\hline $100 / 100$ & $\$ 74.95$ \\
\hline $200 / 200$ & $\$ 89.95$ \\
\hline
\end{tabular}

COMCAST (data-only plans, sample)

\begin{tabular}{|l|l|l}
\hline Down/Up Speeds & Year 1 & Year 2+ \\
\hline $25 / 5$ Mbps & $\$ 29.95$ & $\$ 74.95$ \\
\hline $200 / 10$ & $\$ 49.95$ & $\$ 87.95$ \\
\hline
\end{tabular}

CMLP BUSINESS PLANS

\begin{tabular}{|l|l|l|}
\hline $\begin{array}{l}\text { Download/Upload } \\
\text { Speeds }\end{array}$ & Prices & $\begin{array}{l}\text { Hardware } \\
\text { Replacement } \\
\text { Guarantee }\end{array}$ \\
\hline $50 / 50$ Mbps & $\$ 74.95$ & Next day \\
\hline $100 / 100$ & $\$ 89.95$ & Next day \\
\hline $200 / 200$ & $\$ 149.95$ & 4 hours \\
\hline $300 / 300$ & $\$ 199.95$ & 2 hours \\
\hline $\begin{array}{l}\text { Business Enter- } \\
\text { prise } \\
\text { (Custom service, } \\
\text { up to 1 Gbps) }\end{array}$ & $\begin{array}{l}\text { Custom } \\
\text { quote }\end{array}$ & $\begin{array}{l}\text { As little as 1 } \\
\text { hour }\end{array}$ \\
\hline
\end{tabular}




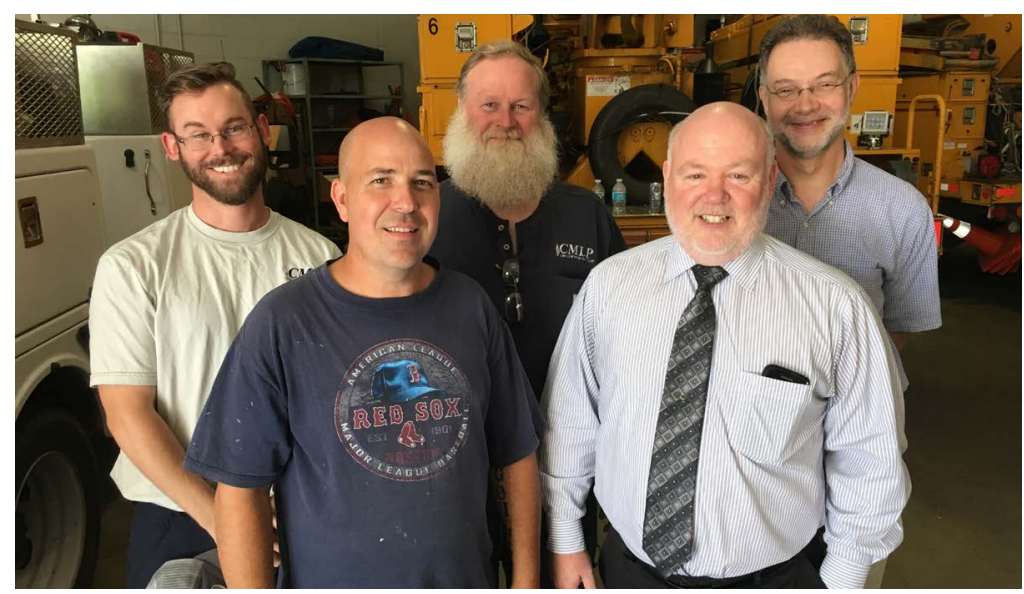

CMLP's telecom team includes (from left) Mike McSheffrey, Marc Goulet, and Tom Power, telecommunications network technicians; Bill Underhill, telecommunications coordinator; and Mark Howell, the town's chief information officer. (Howell also has duties outside the telecom team.)

operations. (In addition, in 2016 CMLP's telecom division spent $\$ 60,000$ to service its debt. This included a $\$ 50,000$ payment on principal.)

CMLP purchases wholesale Internet access from two vendors, DSCl and Lightower, via connection points at the town boundary. Those two companies - as well as Concord Academy, a private school-now also lease some of CMLP's fiber, paying a total of about $\$ 88,000$ a year to use far less than 1 percent of the system's capacity. ${ }^{33}$

Existing multi-dwelling units (MDUs) were not eligible for the service, due mainly to exclusive contracts many MDUs have with incumbent cable companies. However, by working with a developer, CMLP made a deal to provide service to a new 64-unit residential and commercial complex near the West Concord commuter rail station. It is now providing service to residents there. ${ }^{34}$

Individual business owners say they have benefited. In 2012 Jim Leahy, manager of Debra's Natural Gourmet, a grocery store in Concord, adopted a system requiring high-speed Internet access for credit card processing and inventory management. Because Comcast didn't serve his building, Leahy started paying $\$ 400$ a month to lease lines from Verizon. But in 2014 he was able to get service from CMLP and start paying only $\$ 89$ monthly for high-speed fiber connectivity. An additional connection at Leahy's Concord home allows him to monitor inventory without driving to the store. ${ }^{35}$

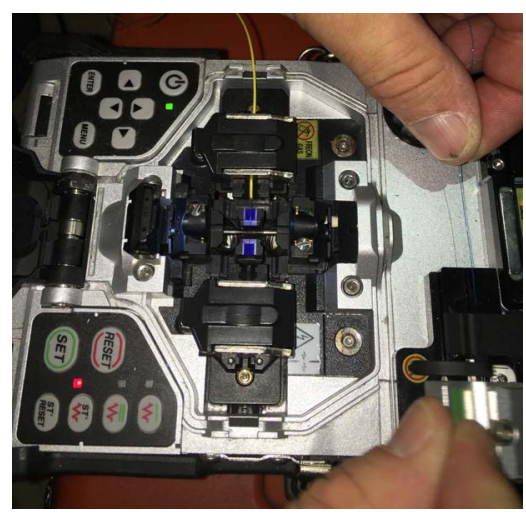

To enable town-employed technicians to make home connections,

CMLP invested $\$ 12,000$ in a fiber-splicing machine.

Left, optical fiber is aligned in the device.

Below, the completed splice.

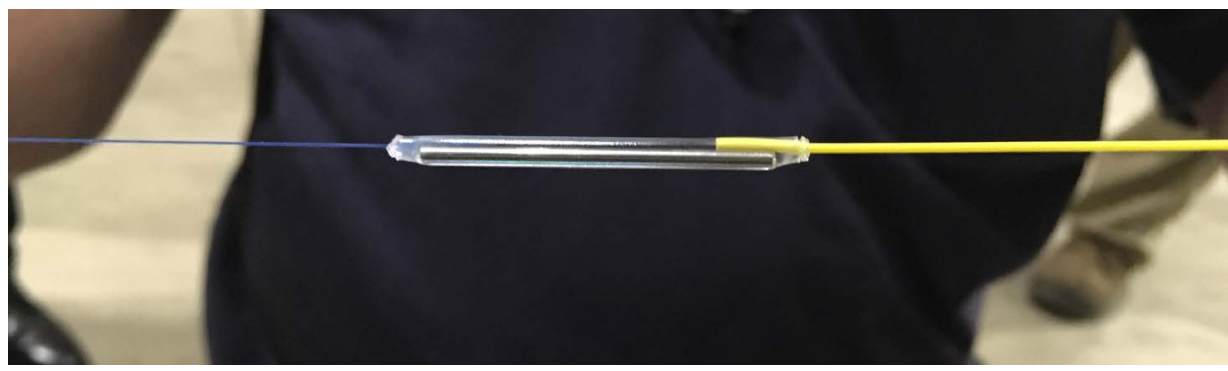




\section{IV: Putting the Smart Grid to Work}

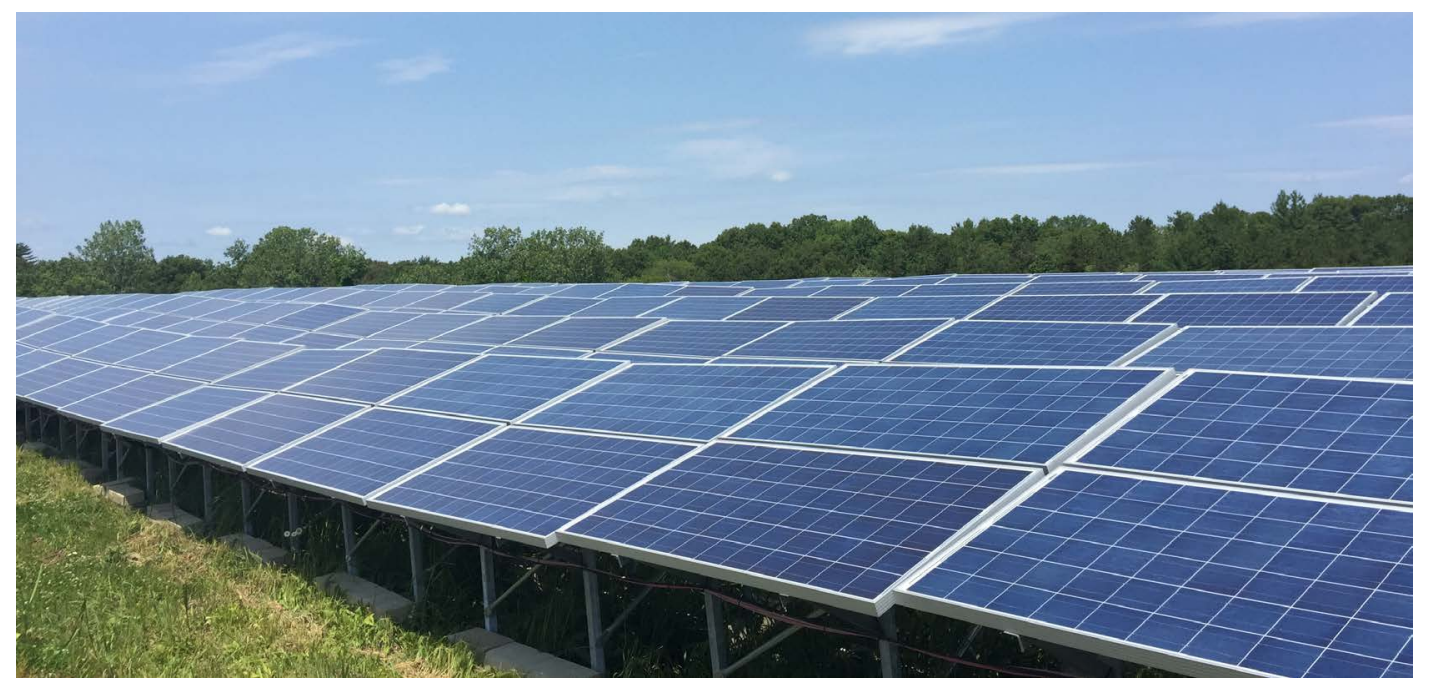

Concord's generation capacity includes this solar facility on an old landfill, which generates up to 1.7 megawatts of electricity. A second large array in town can generate 4.5 megawatts.

\section{LAUNCHING A SMART GRID STRATEGIC PLAN}

In January of 2016, 195 nations signed the Paris Agreement, committing nearly every country in the world to reducing greenhouse gas emissions to help stave off the worst effects of climate change. ${ }^{36}$ One month later, Concord's Select Board acknowledged the Paris Agreement in creating an Energy Future Task Force to find ways to reduce local emissions. ${ }^{37}$

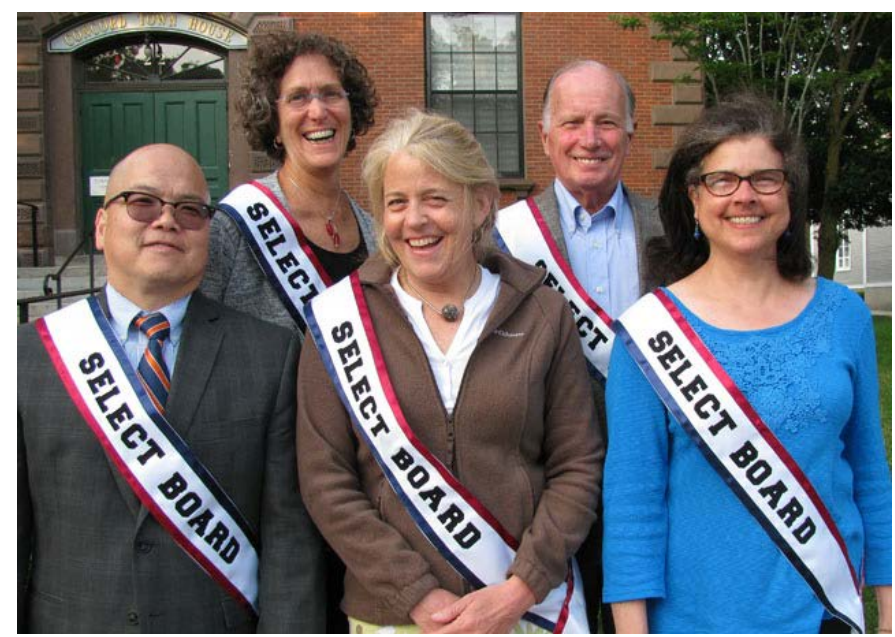

Concord Select Board members Steven Ng, Alice Kaufman, Jane Hotchkiss, Michael Lawson, and Carmin Reiss created an Energy Future Task Force in 2016.
CMLP and its smart grid are a key focus of that effort. In 2016 CMLP launched a strategic plan for the utility, awarding a planning contract to Industrial Economics of Cambridge, Massachusetts, and Optimal Energy of Hinesburg, Vermont. CMLP is seeking a top-to-bottom look at how it communicates with customers, how it sets rates, and how it can use its smart grid to add technologies that will help reduce greenhouse gas emissions. ${ }^{38}$

Human-caused emissions have resulted in a 43 percent increase in the levels of greenhouse gases in the atmosphere; these gases are the principal driver of global warming and disruptive climate change. ${ }^{39}$ And in the United States, 31 percent of greenhouse gas emissions come from electricity generation. ${ }^{40}$ Smart grids like the one in Concord are a key front in the fight to reduce such emissions, because they can allow the management of fluctuating wind and solar power and energy storage technologies.

Concord may consider new types of timebased rates, including ones pegged to real-time wholesale prices. It will examine new ways to increase the number of distributed storage units, including overnight storage of energy in 


\section{THE PROBLEM WITH PEAK POWER}

About 90 percent of the time CMLP needs to provide only 26 megawatts of electricity. But it also must be able to provide as much as the all-time peak of 46 megawatts. It would like to cut its peak.

Percentage of Time CMLP's Load Is Less Than the Specified Consumption Level, in Megawatts

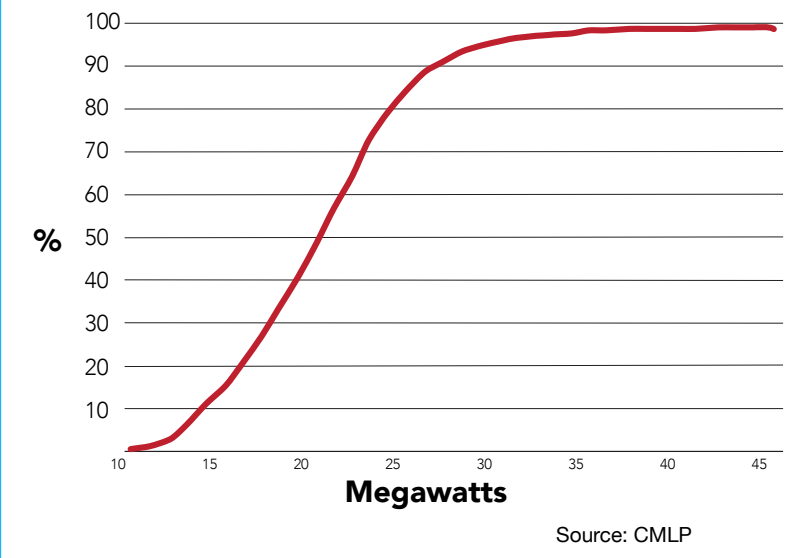

\section{SURGE IN SOLAR GENERATION}

By late 2015, 236 CMLP customers had installed solar panels that produce nearly 2.4 megawatts of electricty at times of peak sunshine. CMLP is planning for how its smart grid can manage the growing but fluctuating inputs of solar power.

CMLP Customers' Solar Generation Capacity (kW)

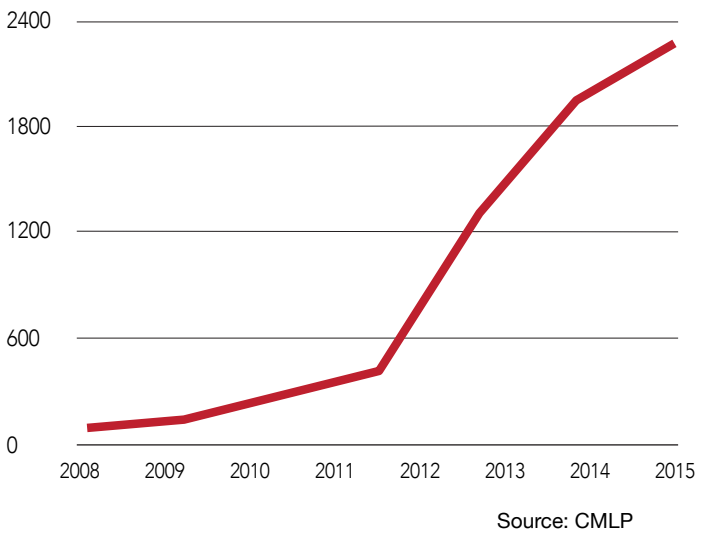

ice that can be used to cool buildings during the day or adding more systems that store heat overnight in winter; utility-scale energy storage using commercial batteries that are just coming on the market or are coming down in price; and wider use of solar power. The town also recently issued an RFP for solar installations on town-owned property, including rooftops. ${ }^{41}$

One statistic stands out: more than 90 percent of the time, customers of CMLP - as a groupconsume no more than 26 megawatts of electricity. Yet the grid must be engineered to handle as much as 46 megawatts, because that's Concord's all-time peak. ${ }^{42}$ During peak times wholesale power is far more expensive and comes from oil or gas power plants that cycle on and off rapidly and are less efficient and higher-emitting than modern plants than run at a constant rate. And the regional transmission system, Independent System Operator (ISO) New England, sets certain charges that are pegged to the monthly and yearly singlehour peaks. Flattening the rate of electricity consumption, often called "peak shaving," cuts costs, provides system efficiencies, and reduces emissions.

Most immediately, the smart grid will help CMLP manage additional solar generation. Chris Roy, the deputy manager of CMLP, puts it this way: "As we reach renewables saturation on our circuits, we will hopefully be able to use smart meter data to shift load flow and avoid costly system upgrades or, worse, prohibition of further solar installations. All of this relies on a robust fiber backbone and access to systemwide metering data. The smart grid creates new and exciting possibilities." ${ }^{43}$ 


\section{MINING THE SMART GRID FOR SAVINGS AND REVENUE}

Now that Concord has a smart grid, it may be able to create a new source of revenue. CMLP, with the cooperation of customers, can potentially get paid by ISO to use parts of its smart grid to stabilize regional voltage frequencies.

CMLP has 141 customers who own electric heating systems that store heat overnight and discharge it during the daytime. Such heatersknown by the brand name Steffes-use electric elements similar to those in electric stoves to superheat ceramic bricks inside insulated cabinets. (When heat is required, a vent opens and a blower operates.) In the 1980s and 1990s Concord incentivized customers to install these systems to take advantage of favorable wholesale electricity pricing then available overnight in winter.

Under those programs, CMLP controlled the timing of the "charging." CMLP was controlling these heaters by telephone wire connections. During winter, a CMLP technician wouldonce per day-set the length of the overnight charging period based on the next day's predicted weather. But the system lacked precision. It couldn't turn the heaters on or off during the night. And while the system was generally reliable, it provided no feedback on

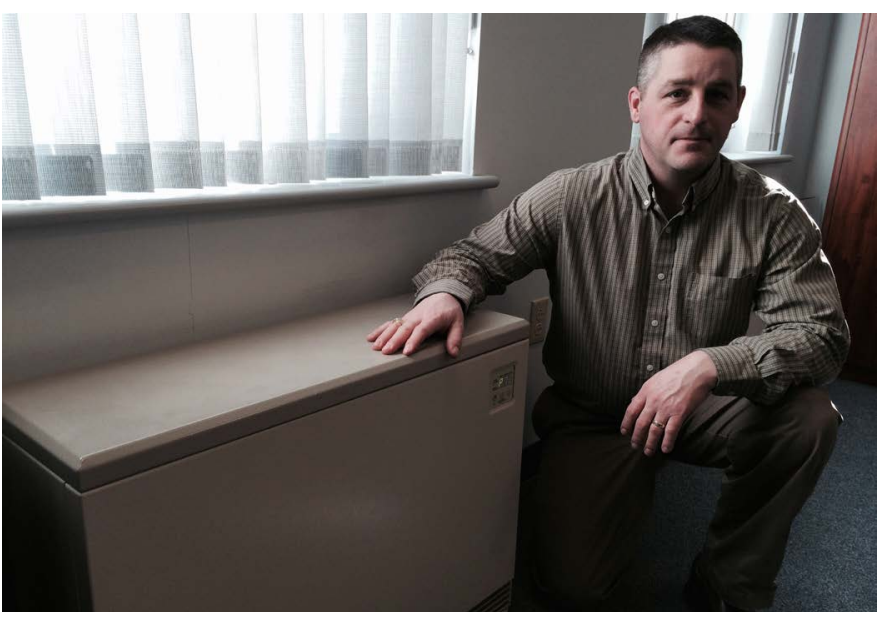

David Wood, CMLP's general manager, with a Steffes heater. The unit is full of ceramic blocks that are heated with electricity overnight and warm his office by day. whether the heaters had actually been turned on or off in response to CMLPs commands. The smart grid made possible precise control and two-way communication.

That capability is very valuable to ISO, which will pay fees to utilities that can instantly and reliably add or subtract electrical loads when demanded by ISO to precisely balance power supply and demand for the regional grid-a task known in engineering jargon as "frequency regulation."

To exploit this opportunity, CMLP has contracted with a company called VCharge, based in Providence, Rhode Island. ${ }^{44}$ The company places a new piece of circuitry in existing heaters to allow precise digital control. The new controller communicates to Concord's grid either through a hardwired fiber connection (if the customer has contracted for Internet access from CMLP and has a home fiber connection) or via a wireless connection to a pole-mounted transmitter that was installed with Concord's smart grid.

When ISO detects that regional supply is exceeding demand (or vice versa), it will send a request for help to the region's distribution utilities, including CMLP. Working as a vendor for CMLP, VCharge can instruct the CMLP heaters to turn on-absorbing excess generationor off, reducing the load, as needed. The heaters then send back a confirmation that they've switched on or off. VCharge sends this confirmation to ISO, managing all of the digital coordination from a data center in Providence.

VCharge has already demonstrated how the system works in a handful of units. Bob Chatham, a principal with VCharge, estimates the potential payments from ISO would be $\$ 125,000$ a year based on the prices ISO is now paying for frequency regulation. (VCharge would get half in exchange for installing the hardware and managing the system, leaving Concord with $\$ 62,500$ in revenue. $)^{45}$ 
In theory, more savings are possible. About 360 CMLP customers have allowed CMLP to put controls on electric water heaters (which also consume large amounts of electricity), and as many as 1,000 hot water heaters may exist in the district. VCharge estimates that controlling these digitally via the smart grid for frequency regulation could provide another $\$ 125,000$ in revenue, which again would be split between the town and the vendor. ${ }^{46}$

These potential revenue opportunities, while still theoretical, are a bright spot for Concord. There have also been disappointments. CMLP had hoped it could cut peak demand if it installed grid-controlled smart thermostats in customers' homes to allow CMLP to turn up thermostats to cut air-conditioning demand during peak times. (Customers would receive incentives to participate.) In a pilot project, the new thermostats in many cases proved incompatible with the control systems on cooling systems in customer homes; CMLP is using its strategic planning process to examine a full range of options for achieving peak-hour reductions. ${ }^{47}$

\section{STUDYING DATA TO IMPROVE OPERATIONS}

Concord is only at the beginning of the process of leveraging its smart grid to generate revenue, achieve system efficiencies, and reduce emissions. As part of its planning, it has also launched a data-analysis study.

CMLP is generating lots of data about its customers' energy consumption. CMLP has entered into a contract with a data-analytics firm, Sagewell, to figure out how best to promote, through rates and rebates, the use of electric heating and cooling to cut peak usage. In particular, Sagewell has been asked by CMLP to identify ways to encourage customers to use electric heat-pump devices that that extract heat from the outside air in winter for home heating, or from the interior air in summer for cooling, ${ }^{48}$ because such units are more efficient than traditional compressors.

At the root of the data-gathering effort are 878 smart meters that send data about home energy consumption back to the utility at 15-minute intervals. Analyzing fluctuations in consumption can provide CMLP with key insights, including whether the home has an electric water heater or a central air-conditioning unit (CMLP might then approach these customers to offer incentives for cutting peak-hour use of these high-demand appliances), and what times usage is highest.

Sagewell will generate a dashboard showing the hourly, daily, monthly, and annual consumption for each customer and costs and revenue associated with this consumption, and compare this with data from a control group. Then it can suggest ways to revise rates and incentives in ways to meet town goals, including cutting peak demand and reducing emissions associated with electricity production. Sagewell's contract

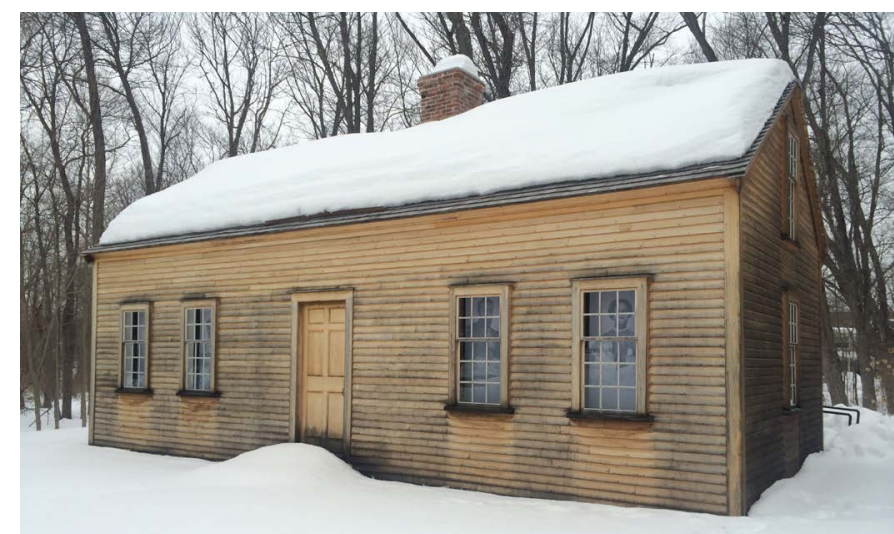

This is the restored home originally built by Caesar Robbins, a former slave who may have fought at the North Bridge. Unlike many houses in New England, Robbins' old home now has a fiber connection.

includes provisions meant to protect consumers' privacy. Sagewell will remove names and addresses before analyzing customer data. The company will also aggregate data from other utilities to help in its analysis. ${ }^{49}$ 


\section{V: Future Expansion Possibilities}

Concord's focus remains entirely on providing service within the town. But now that CMLP has installed an extensive fiber loop and entered the Internet access business, it is in a position to provide such service to other towns. That's done in some other parts of Massachusetts; Holyoke's light plant provides Internet access service to businesses in neighboring Chicopee. The map at right shows two towns near Concord where such expansion is theoretically possible.

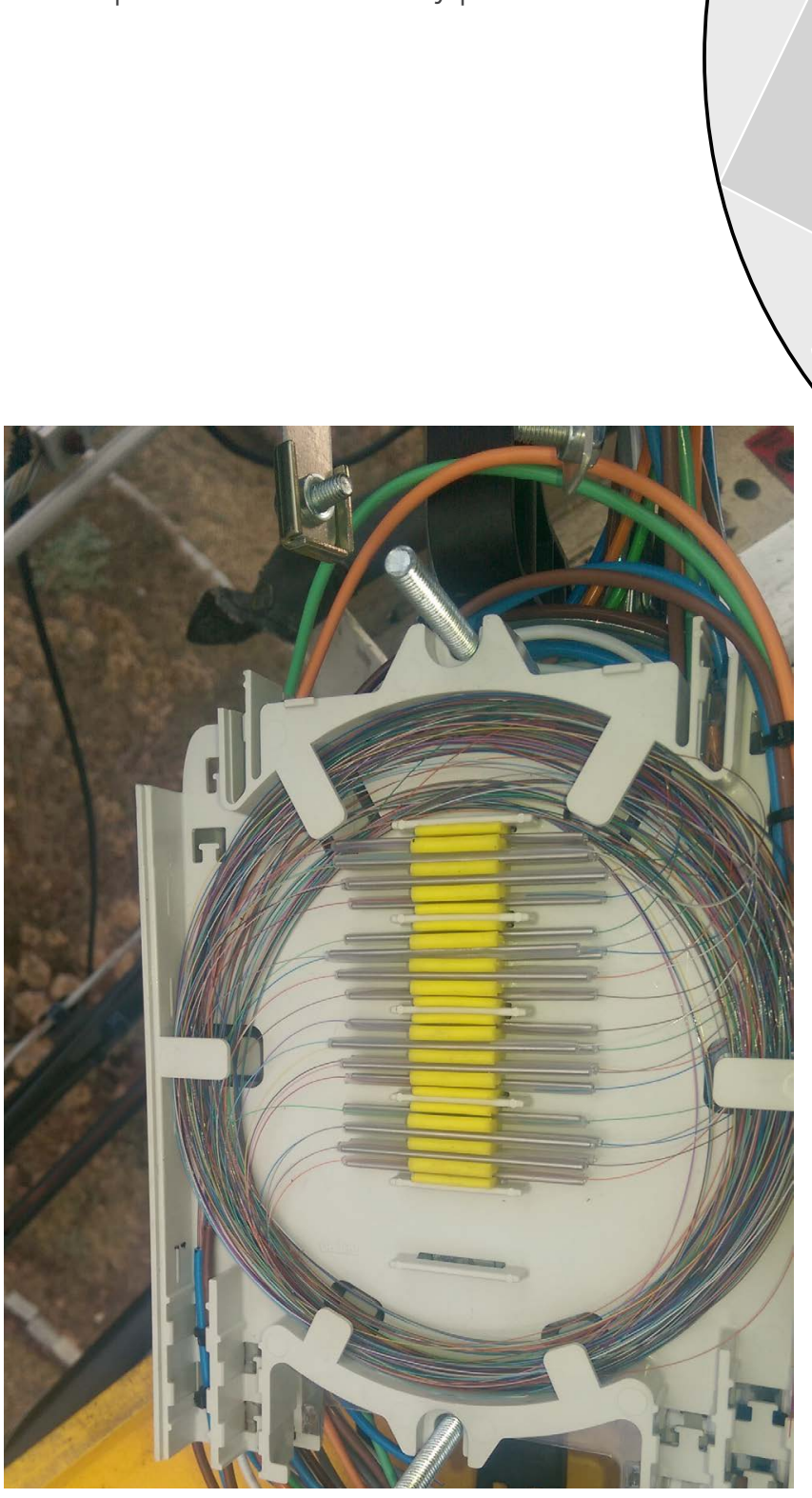

Acton

Carlisle 


\section{CONCLUSION}

In 2009 Concord's Town Meeting cast a key vote that allowed CMLP to build a $\$ 3.9$ million smart grid. This system consisted of 100 miles of versatile fiber and wireless infrastructure that would serve the utility's current and future needs while forming the foundation of an Internet access business. A later $\$ 600,000$ investment funded startup costs for that business.

CMLP's leaders believed they'd quickly shave peak-hour megawatts (and realize a $\$ 120,000$ wholesale energy savings per megawatt) once CMLP installed special grid-controlled thermostats in customers' homes to enable CMLP to scale back air-conditioning use on hot summer days. Implementaton was delayed when a pilot test revealed compatibility problems.

The larger lesson for Concord was clear: fiber is extremely versatile and long-lasting infrastructure whose paybacks come in many forms. It improved Internet access for town citizens, added reliability, generated data that can guide future investments in the power grid, allowed municipal offices to save money, and generated revenue from leasing. Concord is experiencing all of these benefits, and it's still very early days for the project.

One payback was indirect, and came when the town's fiber plans were still in the talking phase. In 2003, Concord's steps toward entering the Internet access business appear to have prodded Comcast into providing significant service upgrades. Today, of course, town residents have a choice of providers. And if they choose fiber service from CMLP, they will enjoy much faster upload speeds than Comcast can provide with its hybrid fibercoaxial network.

In two years, CMLP has signed up 750 data customers. Having gone this far, it could perhaps be more ambitious, such as by moving to offer gigabit service and additional services, such as phone, to further boost competition.

Other paybacks were not part of original projections. CMLP's new infrastructure is saving town taxpayers $\$ 108,000$ a year on police and school communications costs and generating $\$ 88,000$ in leasing revenue. The infrastructure greatly improves CMLP's ability to reliably communicate with home electric heating units and hot water heaters that customers have allowed the utility to switch on and off to aid in peak-load management. And CMLP may be able to generate $\$ 125,000$ in revenue by using the smart grid to help provide for regional grid stability.

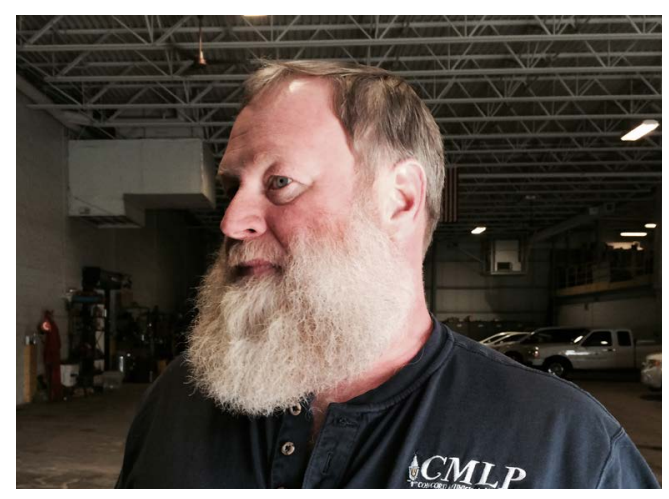

Tom Power, CMLP fiber installer.

All this is only the beginning. At the time of this report's publication, Concord was beginning a new strategic planning process. For example, CMLP is studying whether to offer customers subsidies for installing energy storage systems or converting oil or gas heating systems to electricity-based ones. Data from the smart grid will inform these choices and help CMLP change its electricity rates - such as by creating new time-of-day-based rates-to steer demand to off-peak periods while preserving revenue. And CMLP may find new sources of efficiency and help reduce systemwide greenhouse gas emissions, by means such as using data from its smart grid to identify where CMLP might replace transformers that are needlessly large and replace them with smaller and more efficient ones. 
While the results of these planning efforts are still to come, it's likely that Concord will, over the long term, experience handsome paybacks on its investment. That certainly has been the case in Chattanooga, Tennessee, where robust smart grid paybacks have already been documented. (See "Smart Grid Paybacks: The Chattanooga Example," a companion to this report.) Finally, Concord's debt will be paid off after 15 years, but the fiber infrastructure should last for 30 or more years.

Back in the early 2000s, Concord had a simple goal: fix a market failure that left it with woefully inadequate Internet access. The town was next hit with a lobbying campaign meant to scare taxpayers and stop them from taking action. But voters and town leaders pressed ahead and made investments, recognizing that fiber is versatile and fundamental 21stcentury infrastructure. And they're realizing that fiber can provide a variety of paybacks and community benefits for decades. As the town's $\mathrm{CIO}$, Mark Howell, puts it: "We were definitely ahead of the curve in terms of building it. But this is a 30-year investment, and I have no doubt we will pay back the investment and then some."

For more detail on CMLP's project, readers may visit an online repository of documents now being assembled by Concord resident David Allen: http://concord-trustingtheprocess.org/concbband/conc_bband-hist_timeline.html.

\section{Authors}

David Talbot is a Fellow at the Berkman Klein Center for Internet \& Society at Harvard University. Waide Warner is a Senior Advisor and Lecturer on Law, Cyberlaw Clinic, Harvard Law School. Susan Crawford is John A. Reilly Professor at Harvard Law School and Co-Director of the Berkman Klein Center. Jacob White is a $\mathbf{2 0 1 5}$ graduate of Harvard Law School and an Associate Attorney at Rose Law Firm in Little Rock, Arkansas.

\section{Acknowledgments}

Thanks to Rob Faris, Research Director at the Berkman Klein Center; Daniel Dennis Jones, designer at the Berkman Klein Center; and Kelley McGill, for research assistance.

\section{Funding}

The authors gratefully acknowledge the support of the Open Society Foundations, which provided a grant to the Berkman Klein Center to further research aimed at helping communities explore options for providing high-speed Internet access.

Municipal Fiber Project

23 Everett Street | 2nd Floor | Cambridge, Massachusetts 02138

+1.617.495.7547 | +1.617.495.7641 (fax)

cyber.harvard.edu 


\section{ENDNOTES}

1: Allen, David. Interview by David Talbot. August 14, 2016.

2: "No New Construction of Utility Poles and Overhead Wires Bylaw." Article 28 amended by Article 31. Town of Concord, Massachusetts. April 23, 2001. http://concordma.gov/DocumentCenter/View/879

3: Allen, David. Interview by David Talbot. August 14, 2016.

4: Allen, David. OurConcordNet: A volunteer DSL for Concord, MA. September 12, 2016.

5: Verizon. Accessed December 15, 2015. http://www.verizon.com/about/community/ma tv towns.html

6: Howell, Mark. Interview by David Talbot. June 13, 2016.

7: General Laws: Chapter 164, Section 47C. Massachusetts State Legislature. Accessed September 11, 2016. https://malegislature. gov/Laws/GeneralLaws/Partl/TitleXXII/Chapter164/Section47c

8: Talbot, David, Waide Warner, Carolyn Andersen, Kira Hessekiel, and Daniel Dennis Jones. Holyoke: A Massachusetts Municipal Light Plant Seizes Internet Access Business Opportunities. Report. Berkman Klein Center for Internet \& Society, Harvard University. July 18, 2015. https://cyber.harvard.edu/publications/2015/municipal fiber

9: Sack, Dan. Interview by Jacob White. February 2015.

10: Telecommunications Study Committee Final Report. Memorandum. Concord, MA: Concord Telecommunications Study

Committee, May 14, 2003.

11: General Laws: Chapter 164, Section 47C.

12: Allen, David. Interview by David Talbot. August 14, 2016.

13: Tuerck, David G., PhD, and John Barrett, MSc. Municipal Broadband in Concord: An In-Depth Analysis. PDF. Boston, MA: Beacon Hill Institute, March 2004. http://www.beaconhill.org/BHIStudies/ConcordCable.pdf

14: "Beacon Hill Institute History." Accessed September 12, 2016. http://www.beaconhill.org/Aboutbhi.html

15: "Beacon Hill Institute." Accessed September 12, 2016. http://conservativetransparency.org/recipient/beacon-hill-institute/

16: Krantz, Laura. "Suffolk University Cuts Ties with Conservative Research Group." December 2, 2015. Accessed September 12, 2016. https://www.bostonglobe.com/metro/2015/12/01/suffolk-beacon-hill-institute-sever-ties/joRJw5WHRsZHyaKHhENZzM/story. $\underline{\mathrm{html}}$

17: Community-Based Broadband Solutions: The Benefits of Competition and Choice for Community Development and Highspeed Internet Access. PDF. Washington, D.C.: The Executive Office of the President, January 2015. https://www.whitehouse.gov/sites/ default/files/docs/community-based_broadband_report by executive office of the president.pdf 18: U.S. Dept. of Commerce, National Telecommunications and Information Administration. Potential Interference from Broadband over Power Line (BPL) Systems to Federal Government Radiocommunications at 1.7-80 MHz:

Phase 1 Study. Washington, D.C., April 2004. http://www.ntia.doc.gov/files/ntia/publications/ntia bpl report 04-413 volume i.pdf 19: Citizens for Article 34. 2004. Accessed September 18, 2016. http://archive2004.concord-net-now.org/

20: "Mass Calling Campaign: Concord Residences." Accessed January 4, 2016.

http://archive2004.concord-net-now.org/call_campaign.html

21: Citizens for Article 34. 2004. Accessed September 18, 2016. http://archive2004.concord-net-now.org/

22: Stockton, Dave, and Neil Shaw. FTTP Feasibility Study: Financial Analysis. PPT. Concord, MA: Uptown Services, LLC, April 2007.

23: U.S. Dept. of Energy. Office of Electricity Delivery \& Energy Reliability. Smart Grid. Accessed September $18,2016$.

http://energy.gov/oe/services/technology-development/smart-grid

24: Howell, Mark. Interview by David Talbot. June 12, 2016.

25: Howell, Mark. Interview by David Talbot. June 12, 2016.

26: Fulman, Arthur. Borrowing Authorization for SmartGrid Deployment - Town Meeting Presentation on Article 20. PPT. Concord, MA: Concord Municipal Light Board, April 27, 2009.

27: Presentation to the Finance Committee. PPT. Concord Municipal Light Plant Board. December 18, 2008.

28: Sack, Dan. Smart Grid Budget Memorandum. Concord, MA. July 16, 2009.

29: Town of Concord, MA Debt Service Schedule. FirstSouthwest Public Finance. Concord, MA. May 17, 2011.

30: Howell, Mark. Interview by David Talbot. June 12, 2016.

31: Planning Concord Smart Grid and Broadband Infrastructure and Delivery. Version 1.6. PDF. Concord MA: Concord Municipal Light Plant. April 2013.

32: Service Plans \& Pricing: Concord, MA. Accessed September 11, 2016. http://www.concordma.gov/481/Service-Plans-Pricing

33: Howell, Mark. Interview by David Talbot. January 31, 2017.

34: Howell, Mark. Interview by David Talbot. September 18, 2016.

35: Leahy, Jim. Interview by Jacob White. March 20, 2015.

36: Paris Agreement. United Nations Framework Convention on Climate Change. United Nations. December 2015.

http://unfccc.int/files/essential_background/convention/application/pdf/english_paris agreement.pdf

37: "Energy Future Task Force." Accessed September 18, 2016. http://www.concordma.gov/1098/Energy-Future-Task-Force

38: Request for Proposals: Strategic Planning Consulting Services (RFP \#352). PDF. Town of Concord Municipal Light Plant. Concord, MA. June 9, 2016.

39: "Climate Change: Evidence and Causes." February 27, 2014. Accessed September 11, 2016.

https://royalsociety.org/topics-policy/projects/climate-change-evidence-causes/

40: U.S. Environmental Protection Agency. Fact Sheet: Overview of the Clean Power Plan - Cutting Carbon Pollution from Power

Plants. August, 2015. Accessed September 11, 2016. https://www.epa.gov/cleanpowerplan/fact-sheet-overview-clean-power-plan 
41: Request for Proposals: RFP \#335 Wholesale Energy for the Twenty Year Period Commencing on the Commercial Operations Date of the Solar Facility (SF), Concord MA. PDF. Town of Concord Municipal Light Plant. Concord, MA. December 17, 2015.

42: Request for Proposals: Strategic Planning Consulting Services (RFP\#352). Pg. 17.

43: Roy, Chris. Interview by David Talbot. July 27, 2016.

44: VCharge/Concord Municipal Light Plant Transactive Load Asset Phase III Project Proposal. VCharge Inc. December 7, 2015.

45: Chatham, Bob. Interview by David Talbot. June 6, 2016.

46: Chatham, Bob. Interview by David Talbot. June 6, 2016.

47: Howell, Mark. Interview by David Talbot. Sept. 18, 2016.

48: Data Analysis Services Contract. Town of Concord, MA/Sagewell, Inc. March 14, 2016.

49: Addendum to Data Analysis Services Contract: Data Sharing Agreement. Town of Concord, MA/Sagewell, Inc. March 15, 2016. 